\title{
Effectiveness of Sclerotherapy with Ethanol Amine Oleate in Benign Oral and Perioral Vascular Lesions
}

\author{
Leeza Pradhan', Quazi Billur Rahman² \\ ${ }^{1}$ Oral \& Maxillofacial Surgeon, ${ }^{2}$ Associate Professor and Chairman Department of Oral and Maxillofacial Surgery, BSMMU, Dhaka
}

\begin{abstract}
:
Background: Vascular lesions presentation very with age \& anatomical location. There are no parameters to assess its therapeutic efficacy. Objective: This prospective experimental study was designed to find out the effectiveness of Sclerotherapy with Ethanol Amine Oleate in the treatment of Benign Oral and Perioral Vascular Lesions. Methods: In this study, 32 patients, aged 11/2 to 40 years with oral and perioral vascular lesions were included. Diagnosis was made by accurate history, clinical examination and in some cases Color Doppler examination, MRI and/or Angiogram were done for confirmation. Intralesional injection of Ethanol Amine Oleate was given at an interval of 2weeks between each session. Photographs were also taken during subsequent session to document the effect of injection. Results: At 8weeks after the final Sclerotherapeutic session, the results were graded as: Excellent: for extinguished and symmetrical appearance obtained; Good: for definitive reduction obtained; Fair: for slight reduction obtained and Poor: for lesion unchanged or worsened. Results with grades, excellent and good are considered effective. The efficacy of the treatment was evaluated 8 weeks after the final Sclerotherapeutic session. Out of 32 patients, $34.4 \%$ had excellent result, $53.1 \%$ had good result, $6.3 \%$ had fair result and $6.3 \%$ had poor result. Conclusion: Sclerotherapy with Ethanol Amine Oleate is a safe and less invasive method with minimal risk to the patient. It can be the treatment of choice for symptomatic Vascular lesions.
\end{abstract}

Key words: Vascular Lesions (VLs), Sclerotherapy, Ethanol Amine Oleate (EAO).

[BSMMU J 2011; 4(2):110-115]

\section{Introduction:}

Vascular Lesions of the head and neck encompass a wide range of different lesions. ${ }^{1}$ These are classified by the International Society for the Study of Vascular Anomalies (ISSVA) as Hemangiomas and Vascular Malformations. This classification was first described by Mulliken and Glowacki in 1982 on the basis of clinical behavior and endothelial cell characteristics. Separation of vascular lesions into one of these two groups is of considerable significance relative to the treatment of the patient. Sophisticated laboratory techniques are not necessary to assign a lesion to either of the two major categories: Hemangioma or Vascular Malformation. Diagnosis can usually be made by an accurate history and physical examination. ${ }^{2}$

Vascular Malformations or even Hemangiomas require therapeutic intervention if they start to cause clinical symptoms or personal discomfort. ${ }^{3}$ A number of treatment procedures have been proposed for the management of Benign Vascular Lesions which include Surgical Therapy, Systemic and Intralesional Corticosteroids, Intralesional injection of Sclerosing Agents, and Interferon á, Laser, Embolization, Cryotherapy and Radiation Therapy. ${ }^{4}$ Such numerous and varied modes of treatment actually reflect that no single method is entirely satisfactory in the treatment of vascular lesions.

Sclerotherapy is an effective and conservative technique for the treatment of Benign Vascular Lesions with no risk

Address for Correspondence: Dr. Leeza Pradhan, Department of Oral and Maxillofacial Surgery, BSMMU, Dhaka of hemorrhage. ${ }^{5}$ The agents for sclerotherapy are 5\% Sodium Morruhate, 1\% Polidocal, Sodium Tertradecil Sulfate, Absolute Alcohol and 5\% Ethanol Amine Oleate. ${ }^{6}$

No clinical studies are found which compare the effectiveness of various sclerosing agents. However, Ethanol Amine Oleate (EAO) is a sclerosing agent accepted for skin vascular lesions and oesophageal varices. Nevertheless, few studies deal with Ethanol Amine Oleate efficacy in head and neck vascular lesions particularly oral and perioral lesions. ${ }^{3}$ An open clinical trial was conducted for the first time by Johann et al. in 2005 to support the use of a secure and easy application of Ethanol Amine Oleate in the treatment of 30 Benign Oral Vascular Lesions.

With this idea, the purpose of this study was to evaluate the effectiveness of Ethanol Amine Oleate in the management of Benign Oral and Perioral Vascular Lesions as a sclerosing agent.

\section{Methods:}

The proposed study was presented in front of the Ethical Review Committee, BSMMU and the ethical clearance was achieved.

The cases were selected irrespective of age, gender, religion or socioeconomic status of the patient considering the inclusion and exclusion criteria. 32 cases were selected based on history, clinical examination and imaging techniques like Colour Doppler, CT scan, MRI and /or Angiography.

Informed written consent were taken from the patient or legal guardians after duly informing about the procedure of the treatment, anticipated result and possible advantages, 
disadvantages and complications considering all ethical issues. Photographs of the lesion were taken. Injection 5\% Ethanol Amine Oleate diluted with distilled water in a ratio 1:1 was given intralesionally. The dose was adjusted according to the site and size of the lesion and weight of the patients. Injection was pushed directly into the lesion on multiple sites with 23G or Hypodermic needle until slight elevation of the lesion. The patients were observed on $3^{\text {rd }}$ and $7^{\text {th }}$ day and advised to report if any complications arise. In case with small lesions, where a single session was adequate, follow up were given after 8 weeks for evaluation of the effect of Ethanol Amine Oleate and reduction of size of Vascular Lesion.

In case with large diffuse lesions where single session was not adequate, patients were advised to attend after 2 weeks interval for $2^{\text {nd }}$ and subsequent procedure. Follow up was given after 8weeks of the last session to evaluate the effect of Ethanol Amine Oleate.

Patients were examined for all the parameters that were used to access the lesion pre-operatively and data collected in data collection sheet. Further follow up of the patients were done up to 6 months for any recurrence or complications.

Photographs were also taken during each follow up session to document the effect of injections. Chi-square test and ANOVA test were done to assess the significance. The values of $\mathrm{p}<0.05$ were considered statistically significant. Data analysis was conducted using SPSS software.

\section{Results:}

The patient in this study consisted of 24 males and 8 females with male to female ratio of approximately 3:1. The mean age of the patient was 19 years \pm 11 with a range of $1 \frac{1 / 2}{2}$ to 40 years and $31.7 \%$ of them were in $21-30$ years of age group (Table-I). In a total of 32 lesions, 7 lesions (21.9\%) were found in tongue and upper lip each, which was followed in order of frequency by the buccal mucosa (6 lesions), cheek ( 6 lesions), lower lip (3 lesions), floor of the mouth (2 lesions) and soft palate (1 lesion). On Colour Doppler, 9 lesions were classified to have arterial flow, 8 had venous flow and 7 had both arterial and venous flow (Table- II).

Table-I

Age distribution of the study patients $(n=32)$

\begin{tabular}{lcc}
\hline Age in years & $\begin{array}{c}\text { Number of patients } \\
(\mathrm{n}=32)\end{array}$ & $\begin{array}{c}\text { Percentage } \\
(\%)\end{array}$ \\
\hline$£ 10$ & 9 & 28.1 \\
$11-20$ & 8 & 25.0 \\
$21-30$ & 10 & 31.3 \\
$\geq 31$ & 5 & 15.6 \\
\hline Total & 32 & 100 \\
\hline
\end{tabular}

Mean SD 19.011.0
Table-II

Distribution of the study patients according to type of flow based on colour doppler finding $(n=24)$

\begin{tabular}{lcc}
\hline $\begin{array}{l}\text { Colour Doppler } \\
\text { findings }\end{array}$ & $\begin{array}{c}\text { Number of patients } \\
(\mathrm{n}=24)\end{array}$ & $\begin{array}{c}\text { Percentage } \\
(\%)\end{array}$ \\
\hline Arterial & 9 & 37.5 \\
Both arterial and venous & 7 & 29.2 \\
Venous & 8 & 33.3 \\
\hline Total & 24 & 100 \\
\hline
\end{tabular}

Colour Doppler evaluation show arterial in 9(37.5\%) patients, both arterial and venous in $7(29.2 \%)$, venous in 8(33.3\%).

The mean age of the patients was 19.0 years with standard deviation \pm 11 years and ranged from $1^{1 / 2}$ years to 40 years. Maximum patients were in $21-30$ year age group.

Evaluation of the effectiveness of treatment was based on three criteria: change in color, reduction in size of the lesion and evidence of fibrosis. The response to Sclerotherapy with Ethanol Amine Oleate was then evaluated in 4 patterns: Excellent: extinguished and symmetrical appearance obtained, Good: definitive reduction obtained, Fair: slight reduction obtained and Poor: lesion unchanged or worsened. ${ }^{7}$

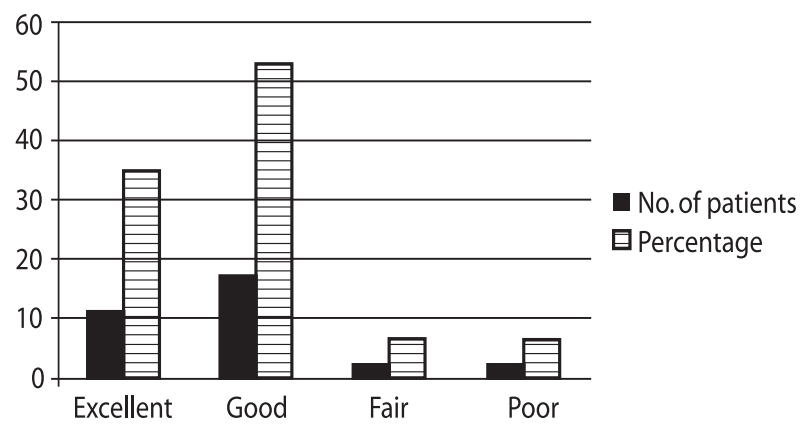

*Grade: Excellent: extinguished and symmetrical appearance obtained, Good response: definitive reduction obtained, Poor response: slight reduction obtained, Poor response: lesion unchanged or worse.

This study was carried out in 32 patients. Out of which $34.4 \%$ had excellent result, $53.1 \%$ had good result, $6.3 \%$ had fair result and $6.3 \%$ had poor result.

Fig.-I: Effectiveness of Sclerotherapy after 8 weeks of Sclerotherapeutic session $(n=32)$ 
Table-III

Age distribution of the study patients according to outcome $(n=32)$

\begin{tabular}{|c|c|c|c|c|c|c|c|c|c|}
\hline \multirow[t]{2}{*}{ Age in years } & \multicolumn{2}{|c|}{ Excellent $(\mathrm{n}=11)$} & \multicolumn{2}{|c|}{$\operatorname{Good}(n=17)$} & \multicolumn{2}{|c|}{ Fair(n=2) } & \multicolumn{2}{|c|}{ Poor(n=2) } & \multirow[t]{2}{*}{ P value } \\
\hline & $\mathrm{n}$ & $\%$ & $\mathrm{n}$ & $\%$ & $\mathrm{n}$ & $\%$ & $\mathrm{n}$ & $\%$ & \\
\hline$\leq 10$ & 2 & 18.2 & 3 & 17.6 & 2 & 100.0 & 2 & 100.0 & \\
\hline $11-20$ & 4 & 36.4 & 4 & 23.5 & 0 & 0.0 & 0 & 0.0 & \\
\hline $21-30$ & 3 & 27.3 & 7 & 41.2 & 0 & 0.0 & 0 & 0.0 & \\
\hline 331 & 2 & 18.2 & 3 & 17.6 & 0 & 0.0 & 0 & 0.0 & \\
\hline Mean \pm SD & 18.6 & \pm 11.0 & 22.5 & \pm 9.8 & 5.5 & \pm 3.5 & 4.5 & \pm 3.5 & $0.033^{\mathrm{s}}$ \\
\hline Range (min - max) & 1.5 & -40 & 7 & -40 & 3 & -8 & 2 & -7 & \\
\hline
\end{tabular}

$\mathrm{s}=$ significant, $\mathrm{ns}=$ not significant

Table-III shows the outcomes according to age of the patients. The mean $( \pm \mathrm{SD})$ age of the patients was $18.6 \pm 11.0$ years with ranged from $1.5-40$ years of excellent recovery patients, $22.5 \pm 9.8$ years with ranged from $7-40$ years in good, $5.5 \pm 3.5$ years with ranged from $3-8$ years in fair and $4.5 \pm 3.5$ years with ranged from $2-7$ years in poor recovery patients. Significant mean age differences were found in different outcome in ANOVA test.

Table-IV

Distribution of the size of the VLs (cm) in the study patients according to outcome ( $n=32$ )

\begin{tabular}{|c|c|c|c|c|c|c|c|c|c|}
\hline \multirow{2}{*}{$\begin{array}{l}\text { Greatest diameter } \\
\text { of the lesion }(\mathrm{cm})\end{array}$} & \multicolumn{2}{|c|}{ Excellent $(\mathrm{n}=11)$} & \multicolumn{2}{|c|}{ Good $(n=2)$} & \multicolumn{2}{|c|}{ Fair $(n=2)$} & \multicolumn{2}{|c|}{ Poor $(n=2)$} & \multirow[t]{2}{*}{ P value } \\
\hline & $\mathrm{n}$ & $\%$ & $\mathrm{n}$ & $\%$ & $n$ & $\%$ & $\mathrm{n}$ & $\%$ & \\
\hline $1-2$ & 8 & 72.7 & 0 & 0.0 & 0 & 0.0 & 0 & 0.0 & \\
\hline $2.1-4$ & 2 & 18.2 & 0 & 0.0 & 1 & 50.0 & 0 & 0.0 & \\
\hline $4.1-6$ & 0 & 0.0 & 13 & 76.5 & 0 & 0.0 & 2 & 100.0 & \\
\hline${ }^{3} 6.1$ & 1 & 9.1 & 4 & 23.5 & 1 & 50.0 & 0 & 0.0 & \\
\hline Mean \pm SD & 2.1 & \pm 1.8 & 4.6 & \pm 2.3 & 7.0 & \pm 4.2 & 5.0 & \pm 0 & $0.011^{\mathrm{S}}$ \\
\hline Range (min - max) & 1 & -7 & 2.5 & -10 & 4 & -10 & 5 & -5 & \\
\hline
\end{tabular}

$\mathrm{s}=$ significant, $\mathrm{ns}=$ not significant

Table-IV shows the outcomes according to size of the lesion of the patients. The mean ( \pm SD) size of the lesion was $2.1 \pm 1.8 \mathrm{~cm}$ with ranged from $1-7 \mathrm{~cm}$ of excellent recovery patients, $4.6 \pm 2.3 \mathrm{~cm}$ with ranged from $2.5-10 \mathrm{~cm}$ in good, $7.0 \pm 4.2 \mathrm{~cm}$ with ranged from $4-10 \mathrm{~cm}$ in fair, $5.0 \mathrm{~cm}$ in two patients of poor recovery, and both patients had $2 \mathrm{~cm}$ lesions size. Significant mean size of the lesions differences were found in different outcome in ANOVA test.

Table-V

Distribution of Type of flow based on Colour Doppler of VLs in the study patients according to outcome $(n=24)$

\begin{tabular}{|c|c|c|c|c|c|c|c|c|c|}
\hline \multirow{2}{*}{$\begin{array}{l}\text { Type of flow based } \\
\text { on color Doppler }\end{array}$} & \multicolumn{2}{|c|}{ Excellent(n=7) } & \multicolumn{2}{|c|}{ Good(n=15) } & \multicolumn{2}{|c|}{ Fair(n=0) } & \multicolumn{2}{|c|}{ Poor(n=2) } & \multirow{2}{*}{ P value } \\
\hline & $\mathrm{n}$ & $\%$ & $\mathrm{n}$ & $\%$ & $\mathrm{n}$ & $\%$ & $\mathrm{n}$ & $\%$ & \\
\hline Arterial & 2 & 28.6 & 7 & 46.7 & 0 & 0.0 & 0 & 0.0 & $0.372^{\mathrm{ns}}$ \\
\hline Both arterial \& venous & 4 & 57.1 & 1 & 6.6 & 0 & 0.0 & 2 & 100.0 & $0.004^{\mathrm{s}}$ \\
\hline Venous & 1 & 14.3 & 7 & 46.7 & 0 & 0.0 & 0 & 0.0 & $0.187^{\text {ns }}$ \\
\hline
\end{tabular}

$\mathrm{s}=$ significant, $\mathrm{ns}=$ not significant

Table-V shows the outcomes according to type of flow based on Colour Doppler of the patients. Colour Doppler evaluation show arterial in 2(28.6\%), both arterial and venous in 4(57.1\%) and venous in 1(14.3\%) in excellent recovery patients. In good recovery patients Colour Doppler found arterial in 7(46.7\%), both arterial and venous in 1(6.6\%) and venous in 7(46.7\%). No Colour Doppler evaluation performed in fair recovery patients. Both arterial and venous were found in Colour Doppler in all poor recovery patients. Significant difference $(\mathrm{p}<0.05)$ was found in lesions with both arterial and venous type of flow in Chi square test. 


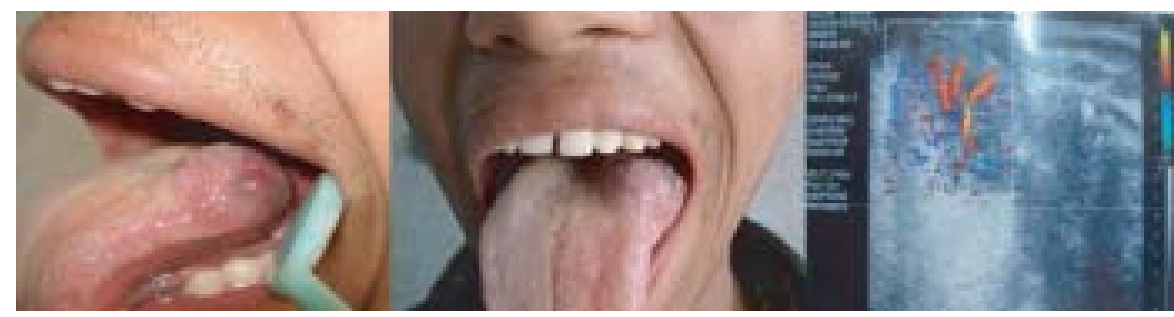

Before Sclerotherapy
Color Doppler of the lesion

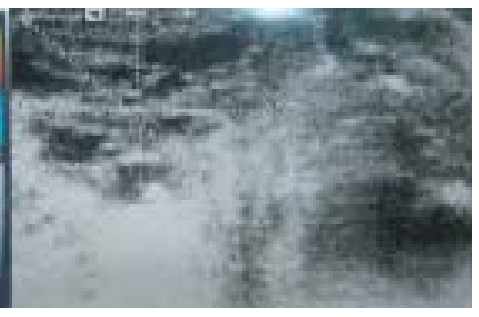

Color Doppler showing the size of the lesion

Photograph-1: Effectiveness of Sclerotherapy after 8 weeks of Sclerotherapeutic session $(n=32)$

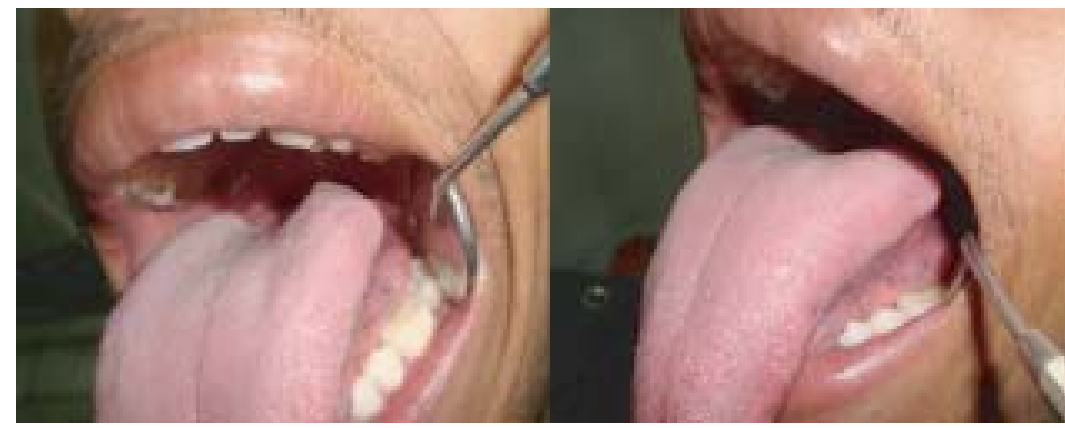

2 Weeks after last Sclerotherapeutic session
After 8 weeks of Sclerotherapy

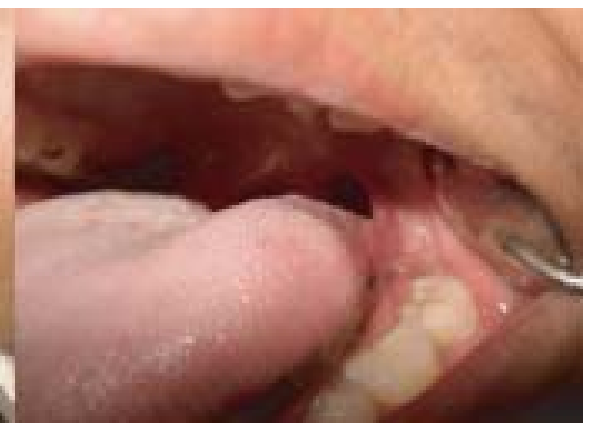

After 8 weeks of Sclerotherapy

Photograph-2: Photographic Demonstration of a patient Undergoes for Sclerotherapy

The outcome of the Sclerotherapy was: 11 (34.4\%) had excellent result, 17 (53.1\%) had good result, 2 (6.3\%) had fair result and 2 (6.3\%) had poor result (Fig.-1) \& photograph.

\section{Discussion:}

Presentation of vascular lesions varies with age, size and anatomic location, and there are no known parameters to assess therapeutic efficacy. ${ }^{8}$ Thus, it is difficult to evaluate the results after the treatment of vascular lesions. This study has tried to objectively evaluate the results on clinical basis aided by comparison of pre-treatment and post-treatment photographs. This study has also attempted to study factors that might predict the result of Sclerotherapy. The study has analyzed the possible association of variables, such as age and sex of the patient, size, age of onset and type of flow of the VLs with the result of Sclerotherapy.

Sclerotherapy is a very conventional method in the treatment of vascular lesions. However, it still is considered as an extremely durable and versatile treatment modality due to its ease, simplicity and safety. The procedure can be repeated as often as it is necessary with minimal complications. Even when Sclerotherapy just reduces the size, it provides a best complement to subsequent surgery.
It decreases the lesion size and changes its nature to more fibrous consistency; resection is therefore accomplished with minimal blood loss. ${ }^{9}$

Johann et al., in 2005 carried out a study in 30 lesions, in which all patients responded to the treatment with total resolution. Similarly in the study by Kaji et al., in 20097, the results in 110 cases treated with EAO was Excellent in 32 (29\%), Good in 48 (44.3\%), Fair in 19 (17\%) and Poor in 11 (10\%). Berenguer et al., 1999, ${ }^{8}$ reported a case of Sclerotherapy of craniofacial venous malformations, where 10 patients (27\%) rated their outcome as near normal, 14 patients (38\%) reported marked improvement, 5 patients (13\%) reported slight improvement and 4 patients (11\%) reported no change. In present study ,out of 32 patients, 11 (34.4\%) had Excellent result, 17 (53.1\%) had Good result, 2 (6.3\%) had Fair result and 2 (6.3\%) had Poor result. The results of above all studies including present study shows same outcome with significant improvement Thus the effect of Sclerotherapy with EAO in Benign Oral and Perioral Vascular Lesions is satisfactory.

The most common local complications of Ethanol Amine Oleate are induration, swelling, pain, cutaneous and mucosal blistering. Systemic complications reported with Ethanol Amine Oleate included anaphylaxis, transient 
bradycardia, thrombophlebitis and thromboembolism. ${ }^{9}$ In this study, maximum patients (90\%) presented with swelling and/or pain immediately after the treatment. They were improved by taking NSAIDS within 72 hours. Choi et al., $2002^{10}$ and Gomes et al., 2006 ${ }^{11}$ also reported similar symptoms in their studies. The pain was due to the expansion of the blood pools. ${ }^{11}$ Cutaneous blistering was seen in one patient (3.3\%); whereas, skin scarring was seen in one patient (3.3\%). However, no severe or life threatening side effects were observed. Swift and Siegler 1986, ${ }^{12}$ claimed that Ethanol Amine Oleate cause less tissue damage from extravasations than other Sclerosants.

In this study, the incidence of complications associated with Sclerotherapy was relatively low which corresponds with the findings of Johann et al., 20054 , Choi et al., $2002^{10}$ and Gomes et al., 2006 ${ }^{11}$. Blistering was found in one case (3\%) which is relatively low than that of Berenguer et al. ${ }^{8}, 3$ 50\% and Lee et al. ${ }^{14}, 34 \%$.

The results were further evaluated to find out any possible correlation with the age and sex of the patient, the size, age of onset and the type of flow of the lesion in the patient. Only age of the patient, size and type of the flow of the VLs were found valuable predictors. In the study by Berenguer et al., $1999^{8}$, they found only sex and number of sclerotherapeutic sessions as valuable predictors in the outcome of Sclerotherapy in craniofacial vascular malformations. They had correlated the outcome with age, sex, location, size, tissues involved, morphology, type of flow and number of sclerotherapeutic sessions.

The mean age \pm SD of the patients was 18.611 .0 years ranged from $1 \frac{1}{2}$ years -40 years of Excellent recovery patients, 22.59.8 years with range from 7- 40 years in Good, 5.53.5 years with range from 3-8 years in Fair and 4.53.5 years with range from 2-7 years in Poor recovery patients. Significant mean age differences were found in different outcome. This meant that adult group of patients responded better to Sclerotherapy than the child group.

In present study, Table IV shows significant mean size of the lesions differences in different outcome in ANOVA test. This meant that VLs with smaller size responded better to Sclerotherapy than those with larger size. This finding could be considered supported by de Lorimier, $1995^{13}$ where he had mentioned that permanent obliteration is easier to achieve in small-diameter vessels than in widely dilated channels. A case study reported by Choi et al., $2002^{10}$, also mentioned that Sclerotherapy is most effective when the vascular spaces are small or when blood flow is slow. Therefore, it is advisable to begin Sclerotherapy as early as possible once the diagnosis is made.

Similarly, In Colour Doppler findings significant differences were found only in lesions with both arterial and venous type of flow.

Perhaps, our failure to statistically support correlation of all the parameters with the outcome of the Sclerotherapy can be ascribed to small size of our samples. Interpretation of the findings must also take into account the fact that Vascular Anomalies evolve and that some patients in this study will require further Sclerotherapy.

\section{Conclusion:}

Sclerotherapy with Ethanol Amine Oleate is a safe and less invasive method, easy to perform repeatedly with minimal risk to the patient. Procedure related complications like induration, swelling, pain and cutaneous or mucosal blistering at the site of injection can occur in some patients. However, these complications are minor and will usually subside in 3- 4 days.

Thus intralesional Sclerotherapy with EAO can be the treatment of choice for symptomatic Vascular lesions.

\section{References:}

1. Van Doorne L, Maeseneer MD, Stricker C, Vanrensbergen R and Stricker M. Diagnosis and treatment of vascular lesions of the lip. Br J Oral Maxillofac Surg 2002; 40: 497-503.

2. Mulliken MD and Glowacki JG. Hemangiomas and vascular Malformations in infants and children: A classification based on endothelial characteristics. Plastic and Reconstructive Surgery 1982; 69: 412-420.

3. Bonan PRF, Miranda LP, Mendes DC, Paula AMB, et al. Effectiveness of low flow vascular lesions sclerosis with monoethanolamine: Report of six cases. Med Oral Pathol Oral Cir Buccal; 2007; 12: E524-7.

4. Johann ACBR, Aguiar MCF, Carmo AV, Gomez RS, et al. Sclerotherapy of benign oral vascular lesion with ethanolamine oleate: An open clinical trial with 30 lesions. Oral Surg Oral Med Oral Pathol Oral Radiol Endod 2005; 100: 579-84.

5. Nichikawa M, Sakamoto K, Hidaka M, Yamashita A, et al. Venous malformation of tongue in a child treated by sclerotherapy with ethanolamine oleate: a case report. J Pediatr Surg 2006; 41: 599-600.

6. Uehara S, Osuga K, Yoneda A, Oue T, et al. Intralesional Sclerotherapy for subcutaneous venous malformations in children. Pediatr Surg Int 2009; 25: 709-713. 
7. Kaji N, Kurita M, Ozaki M, Takushima A, et al. Experience of Sclerotherapy and Embolosclerotherapy using Ethanolamine Oleate for vascular malformations of the head and neck. Scand J Plast Reconstr Surg Hand Surg 2009; 43: 126-136.

8. Berenguer B, Burrows P, Zurakowski D, and Mulliken J. Sclerotherapy of craniofacial Venous Malformations: Complications and Results. Plastic Reconstructive Surgery 1999; 104[1]: pp 1-11.

9. Med Sci Monitor, 2007. Use of sclerosing agent in the management of oral and perioral hemangiomas: Review and case reports. [Online] (Updated $3^{\text {rd }}$ September 2007) Available at: www.MedSciMonit.com

10. Choi YH, Han MH, O-ki K, Cha SH and Chang KH. Craniofacial cavernous venous malformations: percutaneous sclerotherapy with use of Ethanolamine Oleate. J Vasc Interv Radiol 2002; 13: 475-82.

11. Gomes CC, Gomez RS, do Carmo MAV, Castro WH, GalaGarcia A, and Mesquite RA. Mucosal varicosities: case report treated with monoethanolamine oleate. Med Oral Pathol Cir Buccal 2006; 11: E44-6.

12. Swift AC, and Siegler J. Intraturbinate EthanolAmine Oleate as a method of treatment in chronic non specific rhinitis. J Laryngol otol 1986; 100: 417-420.

13. de Lorimier AA. Sclerotherapy for Venous Malformations. Journal of Pediatric Surgery 1995; 30[2]: 188-194.

14. Lee BB, Do YS, Byun HS, Choo LW, et al. Advanced management of venous malformation with ethanol Sclerotherapy: Mid-term results. J Vasc Surg 2003; 37: 533-8. 